\title{
Publication of abstracts presented at the National Pediatric Research Meetings of the Argentine Society of Pediatrics: Related factors
}

\author{
Paula Dominguez, M.D., ${ }^{a}$ María F. Ossorio, M.D., ${ }^{a, b}$ Eduardo Cuestas, M.D., ${ }^{b, c}$ Norberto Giglio, M.D., ${ }^{b, d}$ \\ Carlos Grandi, M.D., b,e Facundo García-Bournissen, M.D., , ${ }^{\text {,d }}$ Santiago Vidaurreta, M.D., b,f \\ Jaime Altcheh, M.D. ${ }^{b, d}$ and Fernando Ferrero, M.D. ${ }^{a, b}$
}

\begin{abstract}
Objectives: Toestimate the proportion of abstracts presented at National Pediatric Research Meetings that are fully-published and describe their design and factors that influence nonpublication.

Methods: Descriptive and analytical study including all abstracts presented at National Pediatric Research Meetings (1998-2011). One author per study was identified and asked to complete a survey on its design, publication and factors associated with non-publication.

Results: Out of 746 abstracts that were submitted, the authors of $522(70 \%)$ completed the survey. Among these, $84.3 \%$ were observational studies and $15.7 \%$, experimental; $34 \%$ had received funding. Two hundred and seventeen abstracts were published subsequently $(41.5 \%, 95 \%$ confidence interval [CI]: 37.3-45.9). Funded studies had better chances of being published (odds ratio [OR]: 2, 95\% CI: 1.4-2.9, $p<0.001$ ). Lack of time, insufficient sample size, and problems with funding were referred as the most common reasons for failure to publish. Conclusion: Among all abstracts presented at National Pediatric Research Meetings, $41.5 \%$ were fully published. Lack of time was the most common reason for unpublished studies.

Key words: medical bibliography, periodic publications, research report.
\end{abstract}

http:/ /dx.doi.org/10.5546/aap.2016.eng.351

a. Hospital General de Niños Pedro de Elizalde, Buenos Aires.

b. Subcommittee of Pediatric Research of the ArgentineSociety of Pediatrics.

c. Hospital Privado de Córdoba, Córdoba.

d. Hospital General de Niños Ricardo Gutiérrez, Buenos Aires.

e. Hospital Materno-infantil Ramón Sardá, Buenos Aires.

f. Hospital Universitario CEMIC, Buenos Aires.

E-mail address: Paula Domínguez, M.D. pau.dom@gmail.com

Funding: Paula Domínguez, M.D., received a research fellowship granted by the Argentine Society of Pediatrics for study development.

Conflict of interest: None.

Received: 12-08-2015

Accepted: 02-03-2016

\section{INTRODUCTION}

Few institutions have been more devoted to pediatric health than the Sociedad Argentina de Pediatría (SAP). Some initiatives may have an easily identifiable influence (e.g., an initiative regarding retinopathy of prematurity); however, the results of others, which may have a major impact, are not so easily identifiable (e.g., continuous education activities). Finally, research activities promoted by the SAP, aimed at encouraging the development of a critical approach and original knowledge among health care providers, will allow to design and/or validate tools and strategies that will directly help to prevent pediatric morbidity and mortality. This study included the National Pediatric Research Meetings conducted by the SAP for the past 18 years.

Research may only be deemed completed once its results are made available and subjected to peer review, turning publication into its final goal. However, only a limited number of abstracts presented at scientific meetings are published in full. ${ }^{1,2}$ Some difficulties have been described in relation to publishing, ${ }^{3,4}$ but their continuous identification may help to develop strategies that facilitate publication.

Regarding the SAP for example, 11\% of abstracts presented at the SAP National Conference are fully published. ${ }^{4}$ However, it may be reasonable to consider that better results could be achieved in relation to specialty events.

Our objective was to estimate the proportion of abstracts presented at the National Pediatric Research Meetings conducted by the SAP between 1998 and 2011 that were fully published. In addition, we described study design and factors related to non-publication.

\section{MATERIAL AND METHODS}

This was a descriptive and analytical study conducted in the second semester of 2014 that included all abstracts presented at National Pediatric Research Meetings (SAP) between 1998 
and 2011. Using the corresponding conference proceedings, one author per study was identified, contacted (in person or via e-mail) and invited to complete a closed, self-administered survey about research publication and the reasons for nonpublication and sources of funding.

Research was considered published if it was in a renowned periodic scientific journal with an international standard serial number (ISSN). We also checked whether the journal was indexed (Medline or Lilacs) or not.

Authors of unpublished studies were asked about likely causes for non-publication (lack of interest, lack of time, disagreement among co-authors, other articles showing similar or contrasting results, results considered not significant, insufficient sample size, difficulties with statistical analysis, authors' pessimism regarding publication acceptance, rejected publications, and others) and to indicate the most important reason.

Regarding published articles, their year of presentation, institution where the main author works, type of research (by objective: basic, clinical, epidemiological or health service), and design (observational or experimental) were recorded. Observational studies were sub-divided into descriptive and analytical types (crosssectional, case-control, and cohort studies), while experimental studies were sub-divided into drug trials (phase I, II, III or IV) and non-drug trials. Also, their scope (international multicenter, national multicenter, local), status (presented as project, ongoing or completed), and presentation (oral or poster) were identified. Survey data were related to abstracts once dissociated from any personal information about the researchers.

Statistical analysis: Categorical outcome measures were expressed in percentages. The $\chi^{2}$ test was used to assess the association between research characteristics (design, status, presentation, and funding) and publication. Odds ratios (ORs) and 95\% confidence intervals (CIs) were estimated; the significance level was established at $p<0.05$. A multivariate analysis (logistic regression) was done including all potential predictors for publication. The SPSS 11.5 software was used.

Ethical considerations: The study was conducted in compliance with Law No. 25326 regarding personal data protection, which warrants an adequate dissociation of personal information. The survey clearly stated the scope of this research and informed subjects that their participation implied their acceptance of the conditions. Approval was obtained from the institutional boards of the institutions where the main authors worked.

\section{RESULTS}

In the studied period, 746 abstracts were submitted; the authors of $522(70 \%)$ completed the survey (Table 1).

Among these, $63 \%$ studies had been completed, $11.7 \%$ were ongoing, and $25.3 \%$ were research projects. Also, $62.3 \%$ were presented orally and $36.4 \%$, as posters; $84.3 \%$ were observational studies (descriptive: $43.9 \%$, cross-

TABLE 1. Distribution of abstracts presented, included in the study and published, by year

\begin{tabular}{lccccc}
\hline Year & $\begin{array}{c}\text { Presented } \\
\text { (n) }\end{array}$ & \multicolumn{2}{c}{ Included in the study } & \multicolumn{2}{c}{ Published } \\
& $(\mathbf{n})$ & $\mathbf{( \% )}$ & (n) & (\%) \\
\hline 1998 & 73 & 51 & 69.9 & 22 & 43.1 \\
1999 & 60 & 44 & 73.3 & 16 & 36.4 \\
2001 & 49 & 44 & 89.8 & 22 & 50.0 \\
2002 & 42 & 34 & 81.0 & 18 & 52.9 \\
2003 & 39 & 17 & 43.6 & 6 & 35.3 \\
2004 & 84 & 33 & 39.3 & 12 & 36.4 \\
2005 & 40 & 33 & 82.5 & 10 & 30.3 \\
2006 & 54 & 33 & 61.1 & 21 & 63.6 \\
2007 & 58 & 41 & 70.7 & 19 & 46.3 \\
2008 & 83 & 62 & 74.7 & 20 & 32.3 \\
2009 & 49 & 39 & 79.6 & 17 & 43.6 \\
2010 & 66 & 48 & 72.7 & 19 & 39.6 \\
2011 & 49 & 43 & 87.8 & 15 & 34.9 \\
Total & $\mathbf{4 4 6}$ & $\mathbf{5 2 2}$ & $\mathbf{7 0 . 0}$ & $\mathbf{2 1 7}$ & $\mathbf{4 1 . 6}$ \\
\hline
\end{tabular}


sectional: $29.5 \%$, case-control: $4 \%$, and cohort: $6.9 \%$ ) and $15.7 \%$ were experimental (drug trials: $4.5 \%)$. One hundred and seventy-eight (34.1\%) studies received funding; most (112) from public sources.

Also, 217 studies (41.5\%, 95\% CI: 37.3-45.9) were fully published; $83 \%$ in indexed journals (Lilacs or Medline). The most common journals for publication included Archivos Argentinos de Pediatría (28\%), Medicina (5\%) and Pediatrics (3.6\%).

The most common reasons described for nonpublication were lack of time $(n=91,29.8 \%)$, insufficient sample size $(\mathrm{n}=34,11.1 \%)$, problems with funding ( $\mathrm{n}=27,8.8 \%)$, pessimism among authors regarding acceptance for publication (n $=20,6.5 \%$ ), and considering results insignificant ( $\mathrm{n}=19,6.2 \%$ ). No author mentioned rejection as a reason for failure to publish.

Studies that had received funding and had been completed had more chances of being published. No association was observed between an experimental design or oral presentation and subsequent publication (Table 2).

After controlling for potential predictors, having received funding and being completed at the time of presentation remained as independent predictors for publication (Table 3).

\section{DISCUSSION}

It was observed that among abstracts presented at the National Pediatric Research Meetings (SAP), 41.5\% were then fully published. This rate is close to the overall average rate $(44.5 \%){ }^{2}$ but above that referred for the Argentine Conferences of Pediatrics (CONARPE) (11.3\%). ${ }^{4}$ Such difference is probably related to the type of abstracts accepted at the CONARPE, where clinical case reports are common but less likely to be published but which are rejected from the National Pediatric Research Meetings, and to the different profile of participants attending these events.

Our findings were similar to those observed in different medical specialty conferences. The analysis of other pediatric societies from Europe and the USA indicates that the rate of publications presented in their annual meetings ranges between $36 \%$ and $60 \% .{ }^{5,6,7}$ As expected, more specific conferences are associated with a higher publication rate, as is the case in our setting of the meetings organized by the Latin American Society for Pediatric Research, achieving a 58\% publication rate. ${ }^{8}$

The most frequently selected journal for publication was Archivos Argentinos de Pediatría. We believe that it may be related to the wide

TABLE 2. Analysis of potential predictors for publication of abstracts included in this study

\begin{tabular}{llccccc}
\hline & & Published & Unpublished & OR & 95\% CI & $p^{*}$ \\
\hline Status & Completed & $175(33.5)$ & $215(41.2)$ & 1.7 & $1.1-2.6$ & $<0.01$ \\
& Project & $42(8.0)$ & $90(17.2)$ & & & \\
Presentation & Oral & $142(27.2)$ & $183(35.1)$ & 1.2 & $0.8-1.8$ & 0.2 \\
& Poster & $75(14.4)$ & $122(23.4)$ & & & \\
\multirow{5}{*}{ Design } & Experimental & $40(7.7)$ & $42(8.0)$ & 1.4 & $0.8-2.7$ & 0.1 \\
& Observational & $177(33.9)$ & $263(50.4)$ & & & \\
& Funding & $94(18.0)$ & $84(16.1)$ & 2 & $1.1-2.9$ & $<0.001$ \\
& No & $123(23.6)$ & $221(42.3)$ & & & \\
\hline
\end{tabular}

${ }^{*} \chi^{2}$ test. OR: odds ratio; CI: confidence interval.

TABLE 3. Multivariate analysis of predictors for publication

\begin{tabular}{lccc}
\hline Outcome measure & OR & $\mathbf{9 5 \% ~ C I}$ & $p$ \\
\hline Completed study & 1.97 & $1.27-3.07$ & 0.02 \\
Oral presentation & 1.44 & $0.97-2.14$ & 0.06 \\
Experimental design & 1.35 & $0.82-2.23$ & 0.23 \\
Funding & 2.01 & $1.38-2.92$ & $<0.01$ \\
\hline
\end{tabular}

OR: odds ratio; CI: confidence interval. 
dissemination of this journal in our setting, but the possibility of publishing in our mother tongue - Spanish - may have also been of influence. ${ }^{9}$

Having received funding was significantly associated with publishing, but design and type of presentation were not; notwithstanding this, for type of presentation (oral), lack of significance may have been due to lack of power $(p=0.06)$. Kleine-Konig ${ }^{6}$ and Shamliyan ${ }^{10}$ observed that experimental studies and abstracts presented orally had more chances of publication than observational ones. Canosa ${ }^{4}$ also observed that oral presentations were associated with greater chances of publication. The characteristics of abstracts presented at our events, which are exclusively research studies, probably account for the fact that having received funding was related to more possibilities of being published. ${ }^{8}$

Consistent with other studies, lack of time was the most common reason referred by authors for non-publication; ${ }^{11}$ so it is worth noting that time to get published should be considered in the schedule of research projects and that it is important to have protected time assigned for research within professional practice. ${ }^{12}$ Likewise, it is worth noting the relevance of doing an adequate feasibility analysis in advance to consider all factors necessary to achieve the required sample size.

For our study we may mention the potential weaknesses of this type of research. Although we were not able to administer the survey to every intended author, the response rate was high $(70 \%)$. All data in relation to publications were checked against the corresponding journals. We also included presentations made up to three years ago, considering that most studies are published in the two years following their presentation. ${ }^{13}$

Our results provide useful information to design strategies aimed at increasing publication rates.

\section{CONCLUSION}

Among all abstracts presented at National Pediatric Research Meetings, more than $40 \%$ were fully published. Having received funding and being completed at the time of presentation increased the chances of publication. Lack of time was the most common problem referred in relation to non-publication.

\section{REFERENCES}

1. Von Elm E, Costanza MC, Walder B, Tramer MR. More insight into the fate of biomedical meeting abstracts: a systematic review. BMC Med Res Methodol 2003;3:12.

2. Scherer RW, Langenberg P, von Elm E. Full publication of results initially presented in abstracts. Cochrane Database Syst Rev 2007;(2):MR000005.

3. Harling L, Craig WR, Russell K, Stevens K,et al. Factors influencing the publication of randomized controlled trials in child health research. Arch Pediatr Adolesc Med 2004;158(10):983-7.

4. Canosa D, Ferrero F, Melamud A, Otero P, et al. Publicación completa de trabajos presentados en el $33^{\circ}$ Congreso Argentino de Pediatria y análisis de factores que impidieron su publicación. Arch Argent Pediatr 2011;109(1):56-9.

5. Macdonald AL, Parsons C, Davenport M. Outcome of abstracts presented at the British Association of Paediatric Surgeons congresses (1999-2008). JPediatr Surg 2012;47(2):38690.

6. Kleine-Konig MT, Schulte TL, Gosheger G, Rödl R, et al. Publication rate of abstracts presented at European Paediatric Orthopaedic Society Annual Meetings, 2006 to 2008. J Pediatr Orthop 2014;34(6):e33-8.

7. Salami K, Alkayed K. Publication bias in pediatric hematology and oncology: analysis of abstracts presented at the annual meeting of the American Society of Pediatric Hematology and Oncology. Pediatr Hematol Oncol 2013;30(3):165-9.

8. Dicembrino M, Anderson M, Vely AG, Ossorio MF, et al. Publicación completa de trabajos presentados en reuniones de una sociedad científica latinoamericana. Arch Argent Pediatr 2014;112(6):532-6.

9. Otero P. El proceso de inclusión de Archivos en la base de datos Medline. Arch Argent Pediatr 2009;107(1):2-3.

10. Shamliyan T,Kane RL.Clinical research involving children: registration, completeness and publication. Pediatrics 2012;129(5):e1291-300.

11. Scherer RW, Ugarte-Gil C, Schmucker C, Meerpohl JJ Authors report lack of time as main reason for unpublished research presented at biomedical conferences: a systematic review. J Clin Epidemiol 2015;68(7):803-10.

12. Dang Do AN, Munchhof AM, Terry C, Emmett T, et al. Research and publication trends in hospital medicine. $J$ Hosp Med 2014;9(3):148-54.

13. Gregory TN, Liu T, Machuk A, Arneja JS. What is the ultimate fate of presented abstracts? The conversion rates of presentations to publications over a five-year period from three North American plastic surgery meetings. Can J Plast Surg 2012;20(1):33-6. 